\title{
A Study on Cross-cultural Pragmatic Failure and Spoken English Teaching
}

\author{
Shi Ying \\ School of Foreign Studies, Xi'an University, 710065
}

Keywords: Cross-Cultural Communication, Pragmatic Failure, Spoken English Teaching

\begin{abstract}
English, as a global language, is playing a vital role. The study of cross-cultural pragmatic failure is of great value in English teaching. This study, conducted at a University in Xi'an, mainly examines the English majors' pragmatic failure in spoken English. A written test is designed to find out students' pragmatic failure and examine their pragmatic competence. Based on the analyses of pragmatic failures, some pedagogical implications for College English majors' Teaching have been put forward.
\end{abstract}

\section{The Current Situation and Significance of the Study}

English, as a global language, is playing a vital role. There is no exception to Chinese college students of English majors who need the competence for both appropriate and correct use of the English language. The National Syllabus indicates that "to develop the skills of listening, speaking, writing and translation has become more and more important with the increase in international communication". However, the author found many Chinese students majored in English could not communicate with the native speakers smoothly even though they had gotten very high scores in English tests. This means that they could not use their acquired linguistic knowledge to communicate appropriately. As a matter of fact, they still commit pragmatic failures which bring about communication breakdowns.

Therefore the second language study object is not only restricted in another language's sound or grammar, it also includes the usage of this language in the different situation. It is realistic significant for China's English teaching to research into the breakdowns and problems in cross-cultural communication, because English teaching does not only impart language knowledge, but also train students' skills of communication and applying English to go on cross-cultural communication. Students earning the pronunciations and grammar rules of a foreign language and mastering quantity of words do not mean that they can communicate successfully with this foreign language. Both sides of communication will produce misunderstanding easily thus the communication will fail if they can not go into the same cultural background in cross-cultural communication.

Pragmatic failures constitute a very important source of intercultural communication breakdown. In the past few decades, many scholars have realized the importance of studying pragmatic failure. But these researches focus only on the description of pragmatic failure or superficial explanation of the causes or just attribute the causes to cultural differences. In fact, the causes of pragmatic failure still need deep and detailed discussion from broader aspects. According to the author's teaching experience, so many pragmatic failures committed by the students can be found. Based on these, the author chooses this topic for thesis. Thus this paper tries to analyze from aspects of pragmalinguistics and sociapragmatics through test and data analysis, and aims to find some pedagogical implications for spoken English teaching.

\section{The Investigation on Pragmatic Failure in Learning Spoken English}

\section{Research questions and Test Designing}

Pragmatic failure has caused many breakdowns and does a lot of harm to intercultural communication. In this study, the researcher tries to find out answers to the following questions:

1) What are the influential factors that cause intercultural pragmatic failure? 
2) What pedagogical implications for English teaching can be put forward?

The subjects were chosen from first-year college students and second- year students of English majors from a University in Xi'an. They had quite a good command of English grammar. The approximate average age was 20 years. They had studied English systematically for at least seven years. 54 students in group 1 were tested without informing anything, but another 54 students in Group 2 were tested after getting a lecture about pragmatic failures. a test on pragmatic competence in English was designed and given.

These questions mainly concerns some pragmatic phenomena. And there are two kinds of questions, which concerning language itself, or, namely, pragmalinguistic questions and sociopragmatic questions. Pragmalinguistic questions and sociopragmatic questions are designed at random. The time for doing this test was unlimited. Thus the students could concentrate themselves completely on the pragmatic aspects of utterance in making their choices. However they must finish the test individually. It was conducted properly in the classroom.

The results are analyzed and discussed in the following. Item 4,7,8,42 are about greeting; item 3 is about addressing; item 2, 5, 9, 10 and 40 are about leave-taking; item 20 to 24, 28, 29, item 30 to 32 , and 35 are about request and response; item 15, 16, 34, 37 to 39 are about complimenting and response; item $11,12,33,44,45$ are about gratitude and response; item 17 to 19 are about offering help; item 1, 13, 14 and 50 are about apologizing; item 25 to 27 and item 36, ,41, 43, 49 are about inviting and advising; item 6 is about telephone speaking. Moreover, there are some items designed with two or more functions. For example, item 39 in the test involves the compliment and acknowledgement as well as initiating a talk. Since there is no clear-cut demarcation between pragmalinguistic failure and sociopragmatic failure, these two categories of pragmatic failure can be found together in many items of the questionnaire.

\section{Results and discussion}

Generally speaking, the survey went along smoothly. According to their answers, the researcher calculated and got the mean of Group 1 is 35.16, the mean of Group 2 is 41.2. Group 2 have better pragmatic competence than Group 1, but the students in two groups still have weak pragmatic competence. The average percentage of Group 1 for the correct responses to the total number of the items amounts to $65 \%$. The average percentage of Group 2 is $76 \%$.

Greeting

The average percentage of this speech act in Group 1 is $66 \%$, in Group 2 is $79.2 \%$. Item 4 and 8 show us how to greet people at the first time. We can see that Chinese students of Eng1ish majors are familiar with this. We often find this answer in the spoken textbook. 59\% in Group 1 use the greeting expressions "pleased to meet you." and "How do you do?". The author interviewed the students who choose B or C in item 4, while $91 \%$ in Group 2 can answer it correctly after getting the lecture. In item 8, some students choose B, they mix up the response of "How do you do" and "How are you?". Item 7 describes a situation that two friends haven't seen each other for a long time. The correct answer is C "How have you been?". Only $63 \%$ of the students use the appropriate greeting expressions in both groups. The answer A and B were used when the other one say "Nice to meet you". Item 42 is used when two friends meet in the morning. $81 \%$ of the students in Group 1 know how to greet in this situation. The correct answer is B, just the sentence "Good morning". Answer A "Have you had the breakfast?" and C "Are you going to work? "concern about privacy. After introduction of this speech act to Group 2, all of them can respond it correctly.

Addressing

$74 \%$ of the Chinese subjects chose an appropriate addressing way to greet in two groups. Answer A: "Mr. Professor." and "Mr. Director" are of the form "Title + Profession", which is not acceptable; answer C: "Principal Brown" and "Director Blake" are of the form "Profession + surname", which is not acceptable. Answer B is the form "Tile +Surname", "Professor Brown" and "Mr. Blake", which is correct. In this item, $11 \%$ of the students choose A and $15 \%$ of the students choose C. They got too limited knowledge about the other rule of addressing about title. Therefore $26 \%$ students make a pragmatic failure according to their own customs.

Leave-taking 
The item 2 is to test the learners' responses of leave-taking. The percentage of correct response here is $100 \%$. According to Chinese culture, guests usually give some excuses for leaving. For Chinese, they think some excuses would be more polite and protect the host's face. For example: "You must be very tired. I'd better leave now." But in English, the intention of leave-taking is always expressed in a direct way and mild tone. Native speakers would like to say "Thank you for the dinner" as the appropriate leave-taking way. But in real cross-cultural communication, Chinese usually use apology when they take leave "I'm sorry to have taken up so much of time" or "I've wasted a lot of your time" as the way of leave-taking. In Question 40, most subjects (81\% in Group 1 and 93\% in Group 2) chose C "I had a very enjoyable time with you, but I have to go now, because I have an important class in the early morning tomorrow." This means that most of the students have realized the difference in this aspect. In item 10, answer A "walk slowly" can not be chosen, answer C "why not immediately?" seems to be impolite. More than $32 \%$ of the students choose the inappropriate answer. They commit the pragmatic failures.

Request and response

Our survey shows the difference in request and corresponding response between Chinese learners and English native speakers. In fact, the chief difference in request is concerned with the degree of directness. English native speakers would like to use an indirect expressions ---usually questions such as "May I..." "Could you..." and "Would you please..." or apologies like "Excuse me, ..." and "I'm sorry,..." to ask the hearer to do something while Chinese prefer the direct ones like "Please..." In item 21, the correct response of the request "Do you mind..." is answer A"Not at all." Besides, although native speakers use questions when making requests, they are not only satisfied with "yes" or "no" answer. They want the hearer to do the thing they have requested. For example: at dinner time, if a speaker requests "Will you pass the salt?" We can not answer "Yes" or "No", this request even can not be refused. We must do something as response. So in item 24 , the correct answer is "All right. What do you want me to get?" whereas most Chinese subjects just answered "Yes", because they didn't regard the intention of the speaker's question as a request. Group 2 get obvious improving in item 30, 31, and 35.

Compliment and response

From the survey, the item 15, 16, 34, 37, 38, 39 of the test are designed to test the informants' knowledge in this area. In item 37, John wanted to compliment his professor. Answer A "I think you are a very strict teacher." Here "strict" is not acceptable. Because Chinese people and English- speaking people have different ideas about what kind of teachers are good and native speakers interpret the word "strict" in a quite different way. In China, "a strict teacher" is the highest compliment for a teacher, it comes from the Chinese saying "An excellent student must have studied under the instruction of a strict teacher." But the foreigner teacher thought he had been a kind and easy-going teacher. Obviously here pragmatic failure emerged. The percentage of correct response to this item is $77 \%$ in Group 1 and $91 \%$ in Group 2. Item 34 and 38 are designed to respond to the compliments. The answer "thank you" is appropriate, which means "acceptance + agreement", "What? Are you kidding?" this kind of responses means "rejection +disagreement".

Gratitude and response

In item 44, Li Ming wants to express his acknowledgement to Mary, the choice B is the most appropriate response. "Thank you very much for your help". In item 45, Xiao Li gives his professor a gift. When he thanks you for your gift, you would thank him as responses to his expression of acknowledgement. 30\% of the learners were correct in item 44 in Group 1, but $72 \%$ of learners in Group 2. The students who choose the wrong answer show me that they are influenced by Chinese sayings in this item. In addition, sometimes Chinese learners are not clear about the correct ways of responding to gratitude and mistakenly use the expressions like "It doesn't matter." or "Never mind", which are always used for apologies. Appropriate responses used by English native speakers should be "My pleasure.", "You are welcome.", "Don't mention it." or "That's ok." In this test, item 11 and 12 just check this aspect. The average percentage of correct response of item 11 is $41 \%$; the percentage of correct response of item 12 is $85 \%$. Most students choose B "That's all right" of 
item 11 which is the reply to apology other than acknowledgement. Answer A "Forget it" is according to Chinese custom, which is not appropriate.

Offer and response

The average of this speech act in two groups is $65 \%$. If you really want to refuse the offer, first you should say "No" to show your attitude, and then thank for his offer. So "No, thanks" is a proper answer. In item 18, it happened between doctor and patient, so we should use the proper way in such situation, "what seems to be the problem" is often used by the doctor. Many of the students in both groups commit mistakes in this item. Chinese people are very modesty as guests. If the host offers something to drink/eat, the visitor often refuses at first. But actually, the visitor wants to drink/eat. If the host is a Chinese, it will appear the following scenes: offer - decline - offer-decline - offer-accept. But if the host is an English, once you refuse, he maybe never offer again. So, if you want to accept the offer, "Yes, please" or "Thanks. That would be nice." is a proper answer to an English host.

Apology and response

In our survey, in Item $1,85 \%$ of Chinese subjects thought "It doesn't matter" or answer B "Never mind" were the correct response to someone's apology "I'm terribly sorry". In English, these sentences cannot be used to accept apology as the equivalent of Chinese response "mei guan xi". Native speakers prefer "That's all right" or "That's OK" as the appropriate response to apology. In item 14, the percentage of the correct answer in Group 1 is only 33\%, while the percentage of the correct answer in Group 2 is $91 \%$. From the comparison, we can find Group 2 are better than Group 1 in this item. The author interviewed the students who choose wrong, they said they judged this question according to their own feeling.

\section{Advising}

In item 36, answer B "You should take good care of yourself" is the Chinese way, which is not proper for advising to a native speaker of English. In item 43, answer B "You'd better go home now" and answer C "you should go home to have a sleep" are too direct, and sound like commands. On the contrary, "Why don't you take some aspirin?" and "If I were you, I would like to go home now." are give some space for the addresses. These two different attitudes of advising in English and Chinese clash in the cross-cultural interactions, the sociopragmatic failures will create. Then the intercultural communication will break down.

\section{Pedagogical Implications for English Teaching}

\section{Enhancing student-centered classroom in English teaching and learning}

The focus of language teaching has shifted from teaching methodology to learners and learning process. Only when learners come to know their situation, their learning strengths, weaknesses, styles and ability to take control of learning, can they be confident enough to involve into their learning and eventually become successful language learners. Tang Jinlan (2002:52) suggests that classroom activities should be more student-centered and interactive in nature.

Classroom teaching should pay more attention to student-centered interaction. Some students complain that the class is too dull and they get tired of listening to teacher's explanation of the text structure and grammar without their participation. Moreover, the students claim that the language teaching in classroom should go beyond grammatical rules and explanation of text structure because they themselves can handle it out of the class. In class, they are expecting for more interesting practical information which is helpful for their communication and an active class environment that all of them can be engaged. Therefore, the teacher should first make students aware of specific speech acts and the accompanying linguistic and pragmatic features that are necessary to produce appropriate and well-received speech acts.

\section{Designing more extracurricular activities}

Classroom hours are limited and we cannot do everything in the classroom. Listening to recordings, watching videos, films, and reading plays and novels are all useful ways to help students to perform certain speech acts, to observe the co-operative principle, and finally to become communicatively competent in cross-culture communication. English recordings, videos, films, 
plays and novels contain authentic conversation which is full of indirect speech act but difficult for Chinese students to understand. If students are guided to read those dialogues, they may become sensitive in interpreting different speech acts. These activities may not yield immediate results, but it does help students understand another culture at deeper levels. The concept of privacy, for example, is an elusive one to most Chinese students, but in having these activities, they will gradually understand why English people treat it as something inviolable.

Cultural environment helps students to experience a foreign atmosphere. Teachers may collect objects and pictures, which display foreign arts, carving architectures and customs and then show them to their students. Films, filmstrips and slides provide cultural insights and a variety of welcome classroom activities. While watching foreign films or TV programs, students should be asked to observe what people eat and wear, what kind of houses Westerners live in and what kinds of activities they hold to show congratulation or comfort.

\section{Reforming testing}

It is common in English classrooms in China that teachers give students a final examination, and the marks they get are considered as the only symbol for their achievement in English learning. In so doing, teachers are adopting what is called summative assessment. It's known that summative assessment is a kind of product evaluation, aimed at gauging the learner's current language competence, skills and attitudes in relevant communicative tasks and contexts. On the contrary, as language learning is an on-going process, and there are many decisions to be made during this process, the author of the present thesis recommends that learner-centered formative assessment be applied. Another more recent dichotomy exists between traditional or standard means of assessment and alternative means, such as the use of portfolios, journals, logs, conferences, and utilizing self-assessment and peer assessment, as well as teacher assessment.

\section{Conclusions and Suggestions}

Foreign language teaching in China has mainly focused on the training of grammatical competence, rather than communicative competence. It results in the frequent occurrence of pragmatic failure without being realized and recognized by the students in real intercultural communication. In intercultural communication, pragmatic failure is unavoidable. It often gives rise to communication breakdown and creates barriers to successful communication. Pragmatic failure may be regarded by native speakers as being deliberately impolite, unfriendly, or even rude. Therefore it is worth our attention to make a research into this issue. The study of cross-cultural pragmatic failure is of great value for both English teaching and learning.

Through the questionnaire in spoken English class, firsthand data has been collected. The analysis of the questionnaire from different angles makes it clear that a lot of reasons can lead to the pragmatic failure in real cross-cultural communication. Based on the research, some pedagogical implications for English Teaching have been put forward.

\section{References}

[1] Bachman, Lyle F. (1990) Fundamental considerations in language testing. Oxford: OUP.

[2] Canale, M \&M. Swain. (1980) Theoretical bases of communicative approaches to second language teaching and testing. Applied Linguistics.

[3] E. Albert, (1968)"Value System," in The International Encyclopedia of the Social Sciences, vol.16. New York: Macamillan.

[4] Ellis, R. (1973) The Study of Second Language Acquistion and Communicative Choice. Standford: Standford University Press,

[5] Li Xiaoju, "In defense of the communicative approach" in Currents of Change in ELT, (eds.:)Richarel Rossener and Rod Bolitho. [M]. Oxford: Oxford University Press. 1990

[6] Louise Cummings. Pragmatics: A Multidisciplinary Perspective [M]. Beijing: Peking University Press 
[7] Patrick R. Moran. Teaching Culture: Perspectives in Practice. [M]. Beijing: Foreign Language Teaching and Research Press: 2003.

[8] Ralph Fasold. The Sociolinguistics of Language [M]. Beijing: Foreign Language Teaching and Research Press: 2000.

[11] Richards, J.C. \& Roger, T. S. Approaches and Methods in Language Teaching. [M]. Beijing: Foreign Language Teaching and Research Press.2000

[12] Samovar, L.A., R.E.Porter. Intercultural Communication: A Reader [M]. Beijing: Foreign Language Teaching and Research Press, 2000. 